\title{
O CUIDADO DE ENFERMAGEM NO PÓS-OPERATÓRIO DE CIRURGIA CARDÍACA: UM ESTUDO DE CASO
}

\author{
The nursing care after cardiac surgery: a case study \\ El cuidado de enfermería en el postoperatorio de cirugía cardiaca: un estudio de caso.
}

Sabrina da Costa Machado Duarte ${ }^{1}$

Marluci Andrade Conceição Stipp²

Maria Gefé da Rosa Mesquita ${ }^{3}$

Marcelle Miranda da Silva ${ }^{4}$

\section{RESUMO}

Os objetivos deste estudo foram descrever as necessidades do paciente no pós-operatório de cirurgia cardíaca identificadas pelos enfermeiros e discutir o cuidado de enfermagem com base em tais necessidades. Trata-se de uma pesquisa descritivoexploratória, de natureza qualitativa, desenvolvida na Unidade Cardiointensiva do Hospital Federal dos Servidores do Estado no Rio de Janeiro. Os dados foram coletados em 2008, por meio de entrevista e observação participante, e analisados mediante a análise de conteúdo. Os dados mostraram uma enfermagem preocupada com o cuidado técnico à beira do leito, porém, desprovida de maior interação com o paciente e sua família. Conclui-se que a adoção plena do processo de enfermagem como metodologia de trabalho contribuirá para uma assistência de melhor qualidade, pautada nas orientações necessárias para cada caso, e para uma melhor informação sobre cuidado envolvendo pacientes, familiares e equipe de enfermagem.

Palavras-chave: Cuidados de enfermagem. Processos de enfermagem. Cirurgia torácica.

\begin{abstract}
The aim of this study was to describe the needs of patients after cardiac surgery identified by the nurses and discuss nursing care based on these findings. A descriptive, exploratory qualitative approach was developed at the cardiac intensive care unit of the Hospital Federal dos Servidores do Estado do Rio de Janeiro. Data collection occurred in 2008, using interview and participant observation techniques and data analysis followed content analysis procedure. Findings show a nursing care compromised with technical care and procedures but devoid the interaction with the patient itself and their family. As conclusion we suggest the adoption of the nursing process as methodology of work to improve quality and contributing to enrich information about patient's care, their family and the nursing team.
\end{abstract}

Keywords: Nursing Care. Nursing Process. Thoracic Surgery.

\section{Resumen}

El objetivo del presente estudio fue describir las necesidades del paciente en el postoperatorio de cirugía cardíaca, según la percepción de los enfermeros, y discutir la atención de enfermería en el postoperatorio de cirugía cardiaca después de las necesidades identificadas. Estudio descriptivoexploratorio, cualitativo, desarrollado en la Unidad Cardio-Intensiva del Hospital Federal de los Servidores del Estado, en Rio de Janeiro. Los datos fueron recogidos en 2008, por medio de entrevistas y observación participante, y fueron analizados por medio del análisis de contenido. Los datos muestran una enfermería preocupada con la atención técnica a la cabecera del paciente, sin embargo, carece de una mayor interacción con el paciente y su familia. Se concluye que la adopción plena del proceso de enfermería como la metodología de trabajo contribuirá para mejorar la calidad de la asistencia, basada en la orientación necesaria para cada caso, contribuyendo para una mejor información sobre la atención que envuelve los pacientes, familiares y el personal de enfermería.

Palabras clave: Atención en Enfermería. Procesos de Enfermería. Cirugía Torácica.

\footnotetext{
${ }^{1}$ Doutoranda em Enfermagem pela Escola de Enfermagem Anna Nery/ UFRJ. Professora Assistente do Departamento de Metodologia da EEAN/ UFRJ. Membro do Núcleo de Pesquisa Gestão em Saúde e Exercício Profissional em Enfermagem - GESPEn. Rio de Janeiro - RJ. Brasil. E-mail: inamachado@globo.com; ²Doutora em Enfermagem pela Escola de Enfermagem Anna Nery/ UFRJ. Professora Associada do Departamento de Metodologia da EEAN/ UFRJ. Membro da Diretoria do Núcleo de Pesquisa Gestão em Saúde e Exercício Profissional em Enfermagem - GESPEn. Rio de Janeiro - RJ. Brasil. E-mail: marlustipp@gmail.com; ${ }^{3}$ Doutoranda em Enfermagem pela Escola de Enfermagem Anna Nery/ UFRJ. Professora Assistente do Departamento de Metodologia da EEAN/ UFRJ. Membro do Núcleo de Pesquisa Gestão em Saúde e Exercício Profissional em Enfermagem - GESPEn. Rio de Janeiro - RJ. Brasil. E-mail: mariagefe@gmail.com; 'DDoutora em Enfermagem pela Escola de Enfermagem Anna Nery/ UFRJ. Professora Adjunta do Departamento de Metodologia da EEAN/ UFRJ. Membro do Núcleo de Pesquisa Gestão em Saúde e Exercício Profissional em Enfermagem - GESPEn. Rio de Janeiro - RJ. Brasil. E-mail: mmarcelle@ia.com.br
} 


\section{CONSIDERAÇÕES INICIAIS}

As doenças cardiovasculares são as principais causas de morte no Brasil. Apresentam-se como fator adicional à elevada representatividade epidemiológica nos índices de morbidade e mortalidade o aumento da esperança de vida ao nascer no país e as mudanças nos hábitos de vida das pessoas, decorrentes, principalmente, dos processos de industrialização e urbanização, que aumentaram a sua exposição aos fatores de risco para o seu desenvolvimento ${ }^{1}$. Apresentam caráter de cronicidade, podendo ser tratadas clínica ou cirurgicamente.

As cirurgias cardíacas, sendo as mais comuns as reconstrutoras, que incluem as revascularizações do miocárdio e as plastias de valva, são intervenções complexas e requerem um tratamento adequado em todas fases operatórias. Entretanto, o pós-operatório (P0) de cirurgias cardíacas, período durante o qual se observa e se assiste a recuperação do paciente em pós-anestésico e em pós-estresse cirúrgico, é marcado pela instabilidade do quadro clínico do paciente, sendo repleto de particularidades, principalmente por se tratar de um período de cuidado crítico.

Várias são as alterações decorrentes do ato cirúrgico em que, na técnica-padrão, o coração é parado e a circulação é mantida através da Circulação Extracorpórea (CEC). Muito se tem discutido a respeito da utilização da CEC nas cirurgias cardíacas e, apesar de as cirurgias sem CEC terem adquirido identidade própria, dadas as evidências de viabilidade e segurança, a opção pela CEC ainda é preferência, apesar do risco eminente de complicações neurológicas ${ }^{2}$.

Dessa forma, o PO de cirurgia cardíaca exige da equipe de saúde observação contínua, tomada de decisão rápida e cuidado de alta complexidade. Os profissionais da equipe de enfermagem são os que compõem esta equipe em maior número e em tempo integral e prestam assistência direta ao paciente visando minimizar possíveis complicações, tais como alterações nos níveis pressóricos, arritmias e isquemias, além de manter o equilíbrio dos sistemas orgânicos, o alívio da dor e do desconforto.

Em prol da qualidade da assistência de enfermagem prestada, o enfermeiro deve organizar e planejar o cuidado a partir da aplicação das etapas metodológicas do processo de enfermagem, de modo a intervir de acordo com as necessidades do paciente de forma individualizada, promover sua rápida recuperação e desospitalização precoce ${ }^{3}$.

A prática assistencial pautada no método científico viabiliza a identificação e o atendimento das necessidades do paciente da melhor forma possível, por meio do histórico, dos diagnósticos de enfermagem, do planejamento, da implementação e da avaliação correta. As necessidades poderão variar ou ter prioridades distintas de acordo com o período do PO, ou seja, se imediato, mediato ou tardio. Para atendê-las adequadamente, o enfermeiro precisa desenvolver habilidades e competência cognitivas, técnicas, organizacionais e de relação interpessoal construtiva, considerando que ora poderão ter caráter objetivo e ora subjetivo.

É destaque a possibilidade de ocorrência da dor no PO, que por seu caráter subjetivo, deve ser valorizada e avaliada cuidadosamente pelo enfermeiro, ressaltando a importância da Sistematização da Assistência de Enfermagem (SAE), que se operacionaliza por meio da aplicação do processo de enfermagem, considerando as variáveis múltiplas que podem repercutir negativamente na evolução do paciente 4 .

Assim, este estudo objetivou descrever as necessidades do paciente no pós-operatório de cirurgia cardíaca identificadas pelos enfermeiros e discutir o cuidado de enfermagem com base em tais necessidades.

\section{MÉTODO}

Estudo descritivo com abordagem qualitativa, que utilizou o método de estudo de caso único, de natureza representativa, cujo objetivo é capturar as circunstâncias e condições de uma situação lugar-comum ou do dia-a-dia 5 .

0 cenário do estudo foi a Unidade Cardiointensiva (UCI) do Hospital Federal dos Servidores do Estado (HFSE), localizado na cidade do Rio de Janeiro, Brasil. Os sujeitos foram 21 enfermeiros atuantes na UCl, sendo adotado como critério de inclusão a sua atuação na UCl por mais de seis meses.

Quanto aos 21 enfermeiros entrevistados, 85,7\% eram do sexo feminino e apenas $14,3 \%$ pertenciam ao sexo masculino, $90,5 \%$ declararam possuir pós-graduação latu-sensu, $76,2 \%$ tinham menos de 10 anos de formação e 95,2\% atuavam na UCl a menos de três anos, o que denota um grupo heterogêneo, fato que pode ser positivo, quando bem aproveitado.

0 estudo foi aprovado pelos Comitês de Ética em Pesquisa do HFSE (parecer n⿳000.296, de 12/11/2007) e da Escola de Enfermagem Anna Nery (parecer n ${ }^{\circ} 091 / 07$, de $31 /$ 10/2007), sendo obedecidos os aspectos éticos que envolvem a pesquisa com seres humanos conforme preconizado pela Resolução n¹96/96 do Conselho Nacional de Saúde.

Os dados foram obtidos por meio da entrevista semiestruturada e observação participante. As entrevistas foram gravadas e transcritas na íntegra. 0 roteiro de entrevista foi constituído pelas seguintes perguntas: Quais as necessidades do paciente que você identifica durante 0 pós-operatório de cirurgia cardíaca? Como é realizado o planejamento do cuidado de enfermagem na Unidade Cardiointensiva?

As entrevistas foram realizadas nos meses de fevereiro a maio de 2008, individualmente, durante os plantões de cada sujeito. A observação participante ocorreu no período entre março e maio de 2008 e constituiu-se de observações do dia a dia, relatadas em um diário de campo.

Os dados obtidos foram submetidos à leitura exaustiva, definindo-se os recortes do texto em unidades de registro. $\mathrm{A}$ unidade de registro é a unidade de significação a codificar e corresponde ao segmento de conteúdo a considerar como 
unidade de base, visando a categorização e a contagem frequencial ${ }^{6}$.

A análise dos dados foi realizada com base no Processo de Enfermagem de Wanda Horta e por bases conceituais da enfermagem que discutem a temática.

\section{RESULTADOS E DISCUSSÃO}

A sistematização da assistência de enfermagem foi discutida por Wanda Horta, utilizando-se a nomenclatura observação sistematizada. Acreditava-se que tal técnica seria o processo para identificar os aspectos físicos dos problemas de enfermagem apresentados pelos pacientes, conforme afirmava Florence Nightingale, que articulava a observação como princípio básico da enfermagem, esperando que os enfermeiros se esforçassem para observar direta ou indiretamente as condições ambientais dos pacientes, para então planejar cuidados eficazes ${ }^{7}$.

Os enfermeiros permanecem durante todo o período de internação hospitalar ao lado do paciente, prestando assistência ininterrupta, o que permite realizar observação direta, bem como identificar as respostas humanas e traçar os diagnósticos de enfermagem, para construir o plano de cuidados a ser implementado de forma individualizada e personalizada ${ }^{7}$.

Com base nesta premissa, foi possível identificar as necessidades manifestadas pelos pacientes no período do PO de cirurgia cardíaca, a partir da observação dos enfermeiros, sendo destacadas as preocupações com os parâmetros hemodinâmicos do paciente e com as Necessidades Humanas Básicas, como sono, repouso e conforto, além de analgesia e controle da dor, conforme depoimentos que seguem.

Você precisa atentar para a monitorização hemodinâmica do paciente, e para a ventilação. Verificar as drenagens. Tudo de forma horária, ficando à beira do leito, sempre pronto para atender qualquer intercorrência. Você vai ficar com o paciente, observando a recuperação dele, de forma a passar o efeito anestésico, tendo todo cuidado, que no pós-operatório imediato é mais apurado. 0 paciente tem necessidade de você ali à beira do leito. Ele precisa do enfermeiro ali, monitorizando tudo. (Enf. 05)

Na hora que o paciente chega, primeiramente é preciso estabilizá-lo, monitorizá-lo, dando prioridade a certos pontos mais importantes, como a pressão arterial e a ventilação mecânica. É preciso baixar os drenos, ver diurese, e toda a parte hemodinâmica a princípio. Praticamente ao mesmo tempo, mas numa sequência lógica de prioridades. (Enf. 12)
A preocupação com a necessidade de manutenção dos parâmetros vitais do paciente pelos enfermeiros torna-se clara. A cirurgia altera a homeostase do organismo, o equilíbrio hidroeletrolítico, os sinais vitais e a temperatura corporal.

Nesse momento será possível investigar e determinar o estado de saúde do paciente, por meio da realização do histórico de enfermagem, primeira etapa metodológica do Processo de Enfermagem ${ }^{8}$. Com vistas à criticidade do paciente no PO de cirurgia cardíaca, o cuidado prestado pela equipe multiprofissional objetiva minimizar complicações, manter o equilíbrio dos sistemas orgânicos, alivio da dor e desconforto e a realização adequada de um plano de alta e orientações.

Os enfermeiros são os responsáveis diretos pelo cuidado à 'beira do leito' e pela percepção das necessidades apresentadas pelo paciente; dessa forma, por uma assistência de qualidade será possível contribuir de forma eficiente para a evolução do paciente no pós-operatório e para sua desospitalização precoce.

A partir da observação participante foi possível perceber e compreender a atuação da equipe de enfermagem no momento da admissão do paciente, verificando-se que muitos dos cuidados preconizados são realizados. Desvela-se também que o cuidar no P0 destina-se a uma assistência abrangente, não apenas pelo arsenal tecnológico que se dispõe para a realização do cuidado, mas também pela atenção e maneira de conduzir o cuidado a pacientes em estado crítico.

De certa forma, o cuidado neste cenário se alicerça em um modelo curativista, que contempla, muitas vezes, as necessidades de cuidados específicos e especializados e também indispensáveis diante da complexidade que envolve o paciente.

Outra preocupação evidenciada foi com a ventilação pulmonar no período transoperatório, em que paciente é induzido ao coma anestésico, à parada cardíaca, à oxigenação e ao bombeamento sanguíneo de forma artificial. 0 paciente perde a capacidade de respirar espontaneamente, necessitando de ventilação mecânica até o restabelecimento da respiração espontânea, necessitando de avaliação constante do seu padrão respiratório ${ }^{9}$.

A dependência da ventilação mecânica é geralmente reservada apenas para os pacientes em período de pósoperatório imediato, ou seja, em torno de 24 horas após a cirurgia, devendo-se, assim que possível, iniciar o desmame do respirador. Contudo, algumas falhas podem ocorrer nas tentativas de desmame, devido aos distúrbios funcionais decorrentes da cirurgia.

0 processo de desmame e extubação do paciente foram relatados pelos enfermeiros como divisores na recuperação durante o PO de cirurgia cardíaca. Dada a estabilidade do paciente, a evolução para sua extubação e desinvasão é geralmente rápida, fato que se deve ao uso de técnicas anestésicas e cirúrgicas melhoradas e a uma mudança no cuidado 
agudo empregado. Contudo, é importante enfatizar que em cirurgias com uso de CEC há um aumento de resistência das vias aéreas, além de aumento na resposta inflamatória ${ }^{10}$.

A busca por uma extubação precoce certamente diminuirá a permanência do paciente na unidade intensiva, além de diminuir o tempo de internação hospitalar. E, assim que o paciente se encontrar hemodinamicamente estável, desperto, responsivo, sem complicações neurológicas, normotérmico, com a dor controlada e sangramento mediastinal reduzido, realizase a extubação no período de $\mathrm{PO}$ mediato.

[...] no pós-operatório mediato, o paciente já está um pouco mais estável. E aí, ele vai necessitar ainda de monitorização de vários parâmetros como PAM (pressão arterial média), como a drenagem, como a diurese, mas você, na maioria das vezes, já tem um doente extubado. (Enf. 02)

No mediato, na verdade, a gente tem que estar de olho na hemodinâmica. Nesse momento, o paciente já está na fase de extubação. E também, eu acho que não muda muito do imediato não, eu acho também que tem que ter aquele controle hemodinâmico e cuidar da parte psicológica junto. Ver o paciente como um todo. (Enf. 14)

$\mathrm{Na}$ UCl, o primeiro banho após a cirurgia cardíaca é realizado no PO mediato. Foi possível observar que o enfermeiro participa diretamente de todo o procedimento, sendo auxiliado pelo auxiliar de enfermagem. 0 banho ocorre no leito, obedecendo-se a técnica-padrão. São realizados os primeiros curativos dos acessos venosos profundos e arteriais, das feridas operatórias e dos óstios de drenos. Busca-se posicionar o paciente adequadamente no leito, bem como avaliar os parâmetros vitais.

Conforme observado na UCl, o banho no leito deve ser realizado de forma criteriosa e coerente, evitando-se molhar os curativos e tracionar sondas, drenos, tubos e outras próteses. Como o paciente está acamado, ele deverá ser cuidadosamente avaliado, minimizando-se a mobilização e a manipulação. Para o enfermeiro, este é o momento ideal para avaliar as condições da pele, primando pela manutenção da integridade cutânea do paciente.

É importante enfatizar que o banho no leito se torna uma necessidade humana essencial para os pacientes que precisam de repouso absoluto, ou cuja mobilidade e locomoção estejam afetadas. É essencial que o grau de dependência destes seja avaliado, primando-se que participem do próprio cuidado, o que certamente contribuirá para um aumento da autoestima e para a alta da UCl. Tal aspecto remete à necessidade do cuidado integral, de forma a buscar atender, especialmente, a dimensão psicológica nesta fase do tratamento e de recobrada da consciência ${ }^{11}$.
[...] a gente sabe que para a maioria dos pacientes, quando vem bem no pós-operatório, é preciso atentar para a parte psicológica, estar presente ao seu lado. Mas, na verdade, a começar por mim, a gente fica muito preocupado com a diurese, com a PAM, com os eletrólitos, com a saturação, com a sincronia do respirador, e o paciente pode estar com dor, ou com medo, afetando a parte psicológica, porque está recobrando a consciência após uma cirurgia extensa, e é todo esse conjunto. (Enf. 14)

Bom, quando a gente entra no pós-operatório mediato, aí leia-se o paciente extubado, ainda com drenos, acordado, mas ainda 'capengando', alterando muito o nível de alerta, enfim, e sentindo, e começando a sentir. O que eu quero dizer, começar a sentir é voltar aos níveis das sensações e de exposição a dor, porque aquele cara foi muito mexido. Eu acho uma preocupação primeira, na minha cabeça é manter o conforto, é deixa-lo confortável. (Enf. 11)

A dor interfere diretamente nos padrões de sono, repouso e manutenção do conforto. É comum, após a cirurgia, o paciente apresentar dor no local da incisão cirúrgica, nos membros inferiores e no local de inserção dos drenos. A dor pode estar relacionada à injúria física decorrente do trauma cirúrgico, da entubação endotraqueal, da irritação causada pelos drenos torácicos, da isquemia miocárdica e da imobilidade no leito imposta pela restrição de movimentos após a cirurgia? .

0 sintoma de dor repercute negativamente na evolução do paciente no P0, ocasionando prejúizos funcionais e orgânicos e refletindo na dificuldade em restabelecer parâmetros vitais adequados, como capacidade respiratória, térmica e cardiocirculatória, em detrimento do agravante cirúrgico. As repercussões da dor no período PO devem ser identificadas mediante avaliação das queixas expostas pelo paciente, acompanhada da avaliação física para identificar as alterações biológicas, bem como comportamentos que se relacionam com a dor, como fácies de dor ${ }^{12}$.

A manutenção do conforto, além da implementação das terapias farmacológicas e não farmacológicas preventivas e direcionadas à sintomatologia apresentada, requer atenção da equipe de enfermagem. Outro fator que deve ser discutido é a manutenção do ambiente terapêutico, considerando-se o ruído como o maior impeditivo deste.

Todas as pessoas que passam pela cirurgia, por mais que estejam clinicamente bem e cheguem sob efeito anestésico, posteriormente sempre comentam que o pior momento é o quando você quer descansar e as pessoas estão passando para lá e para cá, acendendo as luzes, andando, batendo 
o salto alto. Todas as pessoas que passam por essa situação reclamam muito. (Enf. 09)

0 depoimento acima remete à Teoria Ambientalista, cujo foco principal é a potencialização das forças da natureza, por meio da intervenção sobre o meio ambiente, especialmente 0 ambiente físico do paciente. 0 meio ambiente atua sobre o ser humano, produzindo doenças, cabendo ao ser humano reunir suas forças para resistir a elas ou recuperar-se delas $^{13,14}$.

A promoção de um ambiente terapêutico iluminado e silencioso poderá contribuir para o alívio da dor. Deve-se observar também o posicionamento adequado do paciente no leito e a administração de medicamentos analgésicos e sedativos conforme a prescrição médica, objetivando o bemestar do paciente ${ }^{13}$.

Permitir conforto ao paciente em PO de cirurgia cardíaca é expressar através do processo reparador, 0 afastamento da dor e do sofrimento. 0 ambiente hostil e impessoal de uma unidade intensiva exerce influência direta sobre a recuperação do paciente. 0 acender das luzes, os ruídos constantes dos monitores e demais aparatos tecnológicos utilizados, os odores e a baixa temperatura controlada por condicionadores de ar, geram desconfor to e influenciam diretamente na recuperação do paciente.

De acordo com a Teoria Ambientalista, "a enfermeira deve estar atenta, e qualquer sacrifício é válido para assegurar o silêncio, pois nem um bom arejamento nem uma boa assistência serão benéficos para o doente sem o necessário silêncio"13:186.

Além de garantir um adequado ambiente físico e controle da dimensão física, os enfermeiros destacam que é preciso dispensar atenção às suas necessidades psicoemocionais, de forma a contribuir para a sua recuperação imediata.

Eu sinto muita falta disso, da atenção ao paciente depois que ele é extubado. O paciente fica muito ansioso, muito inseguro. 0 que eu observo é que as pessoas não tem muita paciência para ficar muito tempo com o paciente em pós-operatório de cirurgia cardíaca. Então, os pacientes necessitam muito do cuidado de uma pessoa ali do lado pra esclarecer as dúvidas. (Enf. 01)

Eu vejo essa necessidade dele mesmo, digamos que ele quer sair dali, ele quer andar, ele quer estar bem. Eu o vejo muito precisando de alguém próximo a ele, de mais acompanhamento psicológico. Eu vejo que é uma coisa que influencia muito. (Enf. 19)
Nos períodos de pós-operatório mediato e tardio, as necessidades de segurança, de amor e de estima são evidentes, uma vez que o paciente passa a estar ciente de seus medos e anseios e vislumbrando uma recuperação que lhe permita retomar a sua rotina e as suas atividades diárias.

Foi possível observar que o paciente em PO de cirurgia cardíaca necessita de atenção e apoio psicológico constante. Contudo, este é um aspecto falho na assistência de enfermagem realizada na UCl, devido à grande demanda de cuidados e à diversidade de pacientes e patologias existentes.

A ansiedade, definida como preocupação ou medo relacionado à morte, é evidente no período de pós-operatório devido à mudança no ambiente. A UCl é vista como um lugar desconhecido e assustador, distante da família, e das preocupações cotidianas ${ }^{9,11}$.

Assim, a equipe de enfermagem assume um papel diferencial, ofertando apoio psicológico ao paciente, devolvendo-lhe sua autoestima e confiança, além de reconhecer suas competências. "Todas as necessidades estão intimamente inter-relacionadas, uma vez que fazem parte de um todo, o ser humano. É fundamental que se integre o conceito holístico do homem, ele é um todo indivisível, não a soma de suas partes"15:40.

Ainda no âmbito das necessidades, inúmeros fatores interferem nas suas manifestações e atendimento, podendose citar idade, sexo, cultura, fatores socioeconômicos e ciclo saúde-enfermidade. Contudo, todas as necessidades são universais, comuns a todos os seres humanos, variando apenas a sua manifestação e maneira de satisfazê-la ${ }^{15}$.

A Teoria Ambientalista também remonta ao ambiente psicológico, a fim de garantir o bem-estar emocional do paciente. Acredita-se que um ambiente negativo pode resultar em estresse físico, o que poderá afetar emocionalmente 0 paciente. Para que tal problemática seja evitada, deve-se buscar manter a mente estimulada, enfatizando-se a comunicação, dispensando-lhe atenção, evitando interrupções e assuntos desagradáveis ${ }^{13}$.

A necessidade de orientação pela equipe de enfermagem ao paciente submetido à cirurgia cardíaca também esteve presente nos depoimentos dos enfermeiros. Durante o período de internação hospitalar e perioperatório de cirurgia cardíaca, é importante que o paciente seja orientado quanto ao seu estado de saúde e os procedimentos aos quais será submetido. Tais orientações constituem um direito, que deve ser respeitado por toda a equipe interdisciplinar.

Conforme o regulamento do HFSE, o paciente tem direito a ser tratado com consideração e respeito; receber informação sobre sua doença, orientação do tratamento e instruções de recuperação, feitas em termos que possa entender; receber informações sobre o tratamento ou procedimento, a fim de dar consentimento ou recusar tratamento. Exceto em emergências, estas informações devem incluir a descrição do procedimento ou tratamento, os objetivos, 
os riscos médicos envolvidos, tratamentos alternativos ou não tratamento e os riscos envolvidos em cada uma das opções, 0 prognóstico e o direito de saber o nome da pessoa encarregada do procedimento ou tratamento; ser orientado após a alta do hospital; continuar a ser orientado e acompanhado, mesmo nos casos de moléstia crônica ou incurável ${ }^{16}$.

Entretanto, estes direitos nem sempre são respeitados:

Eu acho que falta de informação é uma necessidade também, de conhecimento, porque muitos pacientes vão para a cirurgia sem saber como vão voltar. Eaíretornam para o setor entubados, cheios de fios, completamente monitorizados. Isso causa mais ansiedade e ela poderia ser minimizada a partir do momento que você fornece informações para esse paciente antes de ele ir para o centro cirúrgico. A própria equipe de enfermagem não atenta para importância desse tipo de cuidado. (Enf. 09)

Além de ser um direito, compreender o procedimento ao qual será submetido minimiza a ansiedade do paciente, possibilitando um pós-operatório tranquilo e o restabelecimento em um menor período de tempo. A atividade de orientação é inerente à enfermagem, e por meio da visita pré-operatória, o enfermeiro poderá conhecer o paciente, perceber suas necessidades, seus medos e anseios, intervindo adequadamente com sua orientação.

No momento da visita pré-operatória ou na admissão $\mathrm{UCl}$, o enfermeiro deverá realizar o histórico de enfermagem e exame físico completo, questionar sobre o uso de medicações e próteses; receber e acusar recebimento dos exames pré-operatórios, orientar ao paciente quanto às etapas do PO de cirurgia cardíaca, incluindo o momento do despertar, no pós-imediato, e da necessidade de prótese ventilatória; informar ao paciente quanto ao suporte tecnológico necessário e rotineiramente utilizado na UCl, além de orientar quanto a todos os procedimentos de rotina do pré-operatório imediato ${ }^{17}$.

A visita de enfermagem pré-operatória constitui ainda uma atividade pouco explorada pela enfermagem no HFSE. Sua realização poderá acrescentar benefícios à assistência, sanando algumas necessidades dos pacientes por meio das atividades de orientação, além de permitir a elaboração de um plano de cuidados específico. 0 processo de enfermagem, enquanto método para resolução de problemas e forma de prestar cuidados de enfermagem ao paciente no PO ressalta uma metodologia sistematizada e organizada de desenvolver o cuidado.

A adoção de uma metodologia para a assistência de enfermagem, baseada no processo de enfermagem, contribuirá para um cuidado singular. Estabelecer os diagnósticos de enfermagem, o plano de cuidados e a prescrição de enfermagem possibilitará coordenar a equipe nos cuidados adequados e no atendimento das necessidades do paciente.

$\mathrm{Na}$ elaboração do plano de cuidados, deverão ser observadas todas as necessidades apresentadas pelo paciente, os graus de dependência de cada uma, as necessidades de supervisão e encaminhamento para cada cuidado. A prescrição de enfermagem poderá variar conforme a metodologia empregada, mas deverá respeitar os cuidados prioritários, traduzindo a ação correspondente ao grau de dependência apresentado pelo paciente para a atividade proposta ${ }^{15}$.

É uma coisa que até angustia um pouco. Sempre que eu estou com um paciente antes da cirurgia, eu procuro falar para ele o que vai acontecer, como é que ele vai voltar, que ele vai voltar com dreno, com um tubo na boca, porque ele acorda e está naquela situação. Deve ser desesperador, porque você acha que vai fazer uma cirurgia e que vai voltar tudo bem, com uma cicatriz e tudo bem, porque a maioria das pessoas não explica isso. (Enf. 18)

[...] necessidade de entendimento do que está acontecendo com ele naquele momento. Eu acho que ele fica muito ansioso com essa falta de informação. Se ele está bem, se ele não está bem, porque ele está com dreno, porque ele está com curativo, o que está acontecendo com ele, ele não está entendendo. (Enf. 19)

A necessidade de orientação e a preocupação quanto ao desconhecimento do paciente acerca do procedimento a ser realizado são ilustradas pelos depoimentos dos enfermeiros. A imagem corporal é alterada por procedimentos como tricotomia, punções venosas entre outros procedimentos invasivos. 0 modo como o paciente reage a essas mudanças pode impactar o seu equilíbrio psicoemocional pelo resto de sua vida ${ }^{17}$.

Devido a isso, é necessário enfatizar a importância da preocupação com os sentimentos do paciente em relação a sua vivência na UCl, evidenciando-se o papel do enfermeiro no processo de cuidado.

Muitas vezes, o paciente vai para uma cirurgia extensa e eu que trabalho a noite, eu preparo muito paciente para cirurgia. Então, eu comecei a reparar isso, que a noite não é tranquila. Gera uma ansiedade absurda. Já imaginou você dormir uma noite e saber que daqui a horas você vai está fazendo uma cirurgia? 0 paciente não dorme bem. Ele fica extremamente ansioso. Essa parte tem que ser um pouco mais trabalhada, detalhar como vai ser essa cirurgia. Acho que às vezes, na verdade, pela parte do médico a orientação pode ser muito técnica. Então, eu acho que se a gente se aprimorar um pouco 
mais nessa parte de orientação pré-operatória, vai ser válido, porque depois que eu vim para noite, eu vi como eles ficam ansiosos, como eles ficam mal na noite que antecede a cirurgia. (Enf. 14)

A equipe de enfermagem também é afetada pela ansiedade e falta de orientação do paciente, uma vez que a base da enfermagem é o cuidado, e o mesmo deve ser prestado de forma humanizada. 0 que particulariza o paciente de cirurgia cardíaca é o seu estado emocional. Os momentos de desequilíbrio são constantes, exigindo do enfermeiro sensibilidade e segurança para auxiliá-lo a superar suas dificuldades.

Ao ser submetido à cirurgia cardíaca vivencia-se uma experiência única, repleta de dúvidas, medos e inseguranças. 0 paciente que tem ciência de sua patologia e dos caminhos que precisa percorrer comporta-se de forma segura e tranquila, colaborando com o tratamento prescrito e até mesmo para a alta precoce da instituição hospitalar.

É você dar mais independência para o paciente, sempre orientando em relação ao que ficou, aos remédios que ficaram e continuar aquela monitorização. Ele está sem suporte de oxigênio, ele senta na cadeira, ele está comendo? E aí, o que essas atividades estão the causando? 0 quão independente ele está para realizar aquela atividade e o que aquilo modifica o parâmetro ou não modifica? (Enf. 11)

Passado o período mediato, marcado pela retirada dos drenos e início de uma maior mobilização no leito, é chegado o momento de estimular o paciente a realizar as atividades de autocuidado. Esta será uma forma de (re) inseri-lo à rotina, satisfazendo as necessidades humanas básicas, e os prováveis déficits de autocuidado, tornando-o mais independente da equipe de enfermagem.

Na elaboração do plano de cuidados e da prescrição de enfermagem, devem-se observar todas as necessidades do paciente, e os graus de dependência, e a partir disso determinar o nível de intervenção de enfermagem. A prescrição de enfermagem irá variar de acordo com cada paciente, respeitando-se os cuidados prioritários; deve ser redigida pelo enfermeiro de forma clara e objetiva, traduzindo a ação correspondente ao grau de dependência apresentado pelo paciente para a atividade proposta ${ }^{15}$.

No pós-operatório tardio, o paciente apresenta um nível maior de estabilidade, objetivando-se a cicatrização da ferida cirúrgica e a reabilitação cardíaca.

No pós-operatório tardio, já é um paciente mais estável, não tendo as preocupações como no pósimediato, mas é um paciente ainda que, numa terapia intensiva, vai necessitar de sinais vitais de 4/ 4h, vai necessitar de verificação da diurese, de ficar monitorizado continuamente. Você vai estar atento à aceitação da dieta, aos exames para possiveis parâmetros de infecção. É o momento que você vai desinvadindo esse paciente. (Enf. 02)

Busca-se a retirada dos demais dispositivos invasivos, como cateteres, acessos venosos profundos e da linha arterial média, uma vez que a monitorização invasiva geralmente não é mais necessária. Contudo, deve-se manter um rigoroso balanço hídrico, com registro de infusões e débitos, além do controle da diurese. 0 processo de alta da unidade intensiva para a unidade de internação deve ser iniciado, estimulandose o paciente para o retorno às atividades de autocuidado.

Neste momento pode-se iniciar à Fase I da Reabilitação Cardíaca, gerenciada pelo enfermeiro, e que compreende o período intra-hospitalar, com duração média de quatorze dias para pacientes não complicados e submetidos a procedimento cirúrgico, sob supervisão da equipe interdisciplinar. Prima-se por atividades de educação em saúde e aconselhamentos aos pacientes e seus familiares, por meio de discussões informais. São indicados exercícios de leve intensidade, de forma intermitente, como caminhar e sentar em cadeira de forma supervisionada, evitando-se o repouso prolongado no leito ${ }^{18}$.

As demais Fases (II e III) ocorrerão após a alta hospitalar, em tratamento ambulatorial. As orientações realizadas pela equipe de saúde estimularão a aderência do paciente ao tratamento, de forma a controlar os fatores de risco aos quais estará exposto, evitando recidivas.

A orientação ao paciente no momento da alta fará o diferencial para sua recuperação. Os depoimentos dos enfermeiros confirmam ser esta, uma preocupação daqueles envolvidos com os cuidados no PO de cirurgia cardíaca.

No período tardio, existem várias necessidades, mas acredito que a orientação é a mais importante. Acho que é a parte que acaba deixando falhas. 0 cliente vai de alta, e muitas vezes ele vai cheio de dúvidas que ele mesmo não expõe e a gente acaba deixando também passar despercebido, de como é que vai ser com aquela ferida operatória que ele ganhou de presente e ele vai levar para casa, como é que vai ser o dia a dia dele, o que ele pode comer, o que ele não pode, que tipo de atividade elejápode começar a fazer, se ele pode pentear o cabelo, se ele pode subiruma escada. Eu acho que orientação éalgo que a gente deveria trabalhar melhor nos pacientes no momento da alta. (Enf. 03)

Acho que é muito importante no cuidado dele, você estar orientando o paciente de como que ele vaise manter em casa. Como que vai ser o dia a dia dele 
em casa, no seu ambiente, o cuidado que ele vai ter com a alimentação, quais as medicações que ele vai tomar, os sinais que ele tem que identificar de alguma problemática pra que ele possa novamente procurar o hospital, o que pode vir a ser um risco pra ele, pra que ele procure o hospital. Acho que trabalhar a parte de educação do paciente é fundamental em qualquer pós-operatório, principalmente numa cirurgia cardíaca, porque é um momento que ele tem que se disciplinar. (Enf. 08)

Após a cirurgia, o paciente e seus familiares se deparam com uma nova rotina de vida, sendo fundamental o acesso a todas as informações de forma clara e precisa sobre os novos hábitos de vida a serem adotados. A recuperação inadequada do paciente pode estar diretamente relacionada à deficiência de informações.

É importante enfatizar que, no retorno para a casa após a alta hospitalar, pacientes e familiares se sentem desprotegidos da vigilância da equipe de saúde. Assim, caberá ao enfermeiro a realização das orientações adequadas, considerando que muitas dúvidas surgirão no período pós-alta, devendo-se também avaliar as orientações absorvidas e o nível de compreensão apresentado pelo paciente e seus familiares.

\section{CONSIDERAÇÕES FINAIS}

Neste estudo foi possível descrever as necessidades identificadas nos pacientes no PO de cirurgia cardíaca pelos enfermeiros e discutir o cuidado de enfermagem pautado no método científico, por meio da aplicação das etapas metodológicas do processo de enfermagem, o que valoriza a necessidade da adoção de uma metodologia na assistência de enfermagem durante o PO de cirurgia cardíaca realizada na UCl.

0 cuidado de enfermagem é instituído de acordo com as necessidades dos pacientes, e podem variar de acordo com a fase do pós-operatório, se imediata, mediata ou tardia. Em sua maioria visam à manutenção do equilibrio hemodinâmico do paciente e das suas funções vitais.

Os enfermeiros preocupam-se com a necessidade de diminuir o déficit de conhecimento dos pacientes e seus familiares por meio da educação em saúde, com o objetivo de diminuir o tempo da internação e promover o autocuidado. Além dos aspectos físicos, há destaque para as necessidades psicoemocionais que podem ser evidenciadas no momento e influenciar negativamente na recuperação do paciente, 0 que requer intervenção.

Cabe aos enfermeiros promoverem 0 atendimento das necessidades dos pacientes, consideradas humanas e básicas, trabalhando na perspectiva da interdisciplinaridade. Diante da importância do tema, em decorrência da representatividade epidemiológica das doenças cardíacas que demandam cirurgia, novas investigações são necessárias.

\section{REFERÊNCIAS}

1. Chagas ACP, Zilli EC, Ferreira JFM, Moretti MA, Ramo RF. Saúde cardiovascular do homem brasileiro: visão da Sociedade Brasileira de Cardiologia. Arq Bras Cardiol [online]. 2009; 93(6):584-587. Disponível em: http://www.scielo.br/pdf/abc/v93n6/en 04.pdf

2. Godinho AS, Alves AS, Pereira A, Pereira TS. Cirurgia de revascularização miocárdica com circulação extracorpórea: uma metanálise. Arq Bras Cardiol. 2012; 98 (1): 87-94.

3. Guimarães RCM, Rabelo ER, Moraes MA, Azzolin K. Gravidade de pacientes em pós-operatório de cirurgia cardíaca: uma análise evolutiva segundo 0 TISS-28. Rev Latino-Am Enfermagem. [on-line]. 2010; [citado 15 abr 2012] 18(1): [aprox. 06 telas]. Disponível em: www.eerp.usp.br/rlae.

4. Miranda AFA, Silva LF, Caetano JA, Sousa AC, Almeida PC. Avaliação da intensidade de dor e sinais vitais no pós-operatório de cirurgia cardíaca. Rev Esc Enferm USP. [on-line]. 2011; [citado 2012 jul 03] 45(2): [aprox. 06 telas]. Disponível em: http://www.scielo.br/pdf/reeusp/v45n2/ v45n2a03.pdf.

5. Yin RK. Estudo de caso: planejamento e métodos. Tradução de Daniel Grassi. $4^{\mathrm{a}}$ ed. Porto Alegre: Bookman; 2010.

\section{Bardin L. Análise de conteúdo. 4ª ed. Lisboa: Ed.70; 2010.}

7. Horta WA. A observação sistematizada na identificação dos problemas de enfermagem em seus aspectos físicos [tese livre docência]. Rio de Janeiro: Escola de Enfermagem Anna Nery, Universidade Federal do Rio de Janeiro; 1968.

8. Tannure MC, Gonçalves AMP. Sistematização da Assistência de Enfermagem- SAE: guia prático. Rio de Janeiro: Guanabara Koogan; 2008. $168 \mathrm{p}$.

9. Pivoto FL, Filho WDL, Santos SSC, Almeida MA, Silveiras RS. Diagnósticos de enfermagem em pacientes no período pós-operatório de cirurgias cardíacas. Acta Paul Enferm. 2010; 23(5): 665-70.

10. Machado LB, Negri EM, Bonafé WW, Santos LM, Malbouisson MLS, Carmona MJC. Avaliação dos níveis de citocinas e da função pulmonar de pacientes submetidos à cirurgia cardíaca com circulação extracorpórea. Rev Bras Anestesiol. 2011;61(3): 275-85.

11. Rocha LA, Maia TF, Silva LF. Diagnósticos de enfermagem em pacientes submetidos à cirurgia cardíaca. Rev Bras Enferm. 2006 maio/jun; 59(3): 321-6.

12. Miranda AFA, Silva LF, Caetano JA, Souza AC, Almeida PC. Avaliação da intensidade de dor e sinais vitais no pós-operatório de cirurgia cardíaca. Rev Esc Enferm USP. [on-line]. 2011; [citado 2012 abr 15] 45(2): [aprox. 06 telas]. Disponível em: unw.eeusp.br/reeuspl. 
13. Leopardi MT. Teoria e método em assistência de enfermagem. $2^{\mathrm{a}}$ ed. Florianópolis: Soldasoft; 2006. 396 p.

14. Camponogara S. Saúde e meio ambiente na contemporaneidade: 0 necessário resgate do legado de Florence Nightingale. Esc Anna Nery. 2012 jan/mar; 16(1): 178-84.

15. Horta WA. Processo de enfermagem. São Paulo: EPU , 1979. 97 p. 16. Ministério da Saúde (BR). Hospital Federal dos Servidores do Estado/ RJ. Direitos dos pacientes do H.F.S.E. [citado 2012 abr 15]. Disponível em: http://www.hse.rj.saude.gov.br/cidadao/campanhas/direitos.asp.

17. Leite JL, Braz MR, Nascimento MTF, Stipp MAC. Pós-operatório de cirurgia cardíaca. In: Figueiredo NMA, Viana DL, organizadores. Fundamentos do uso de tecnologias na enfermagem. São Caetano do Sul: Yendis; 2006. p. 253-76.

18. Stipp CA, Leite JL, Stipp MAC, Santos NMP, Machado SC. Enfermagem na reabilitação cardíaca. In: Figueiredo NMA, Stipp MAC, Leite JL, organizadores. Cardiopatias: avaliação e intervenção de enfermagem. São Caetano do Sul: Yendis; 2006. 